\title{
0917 ONTARIO FIRST NATIONS ENVIRONMENTAL SCAN ON INJURIES AND INJURY PREVENTION
}

S Cote-Meek, F Assinewe, D Jones-Keeshig*, A Macpherson* Correspondence: Chiefs in Ontario, 111 Peter St, Suite 804, Toronto, On, M5V 2H1, Canada

10.1136/ip.2010.029215.917

Background Injuries are the leading cause of death among First Nations in Canada from 1 to 44 years, Health Canada 2001. The Ontario First Nation population was 175178 within 133 First Nation communities in 2008. Ontario First Nations identified Motor Vehicle Collisions, Violence including Suicide and Falls, as injury issues and recommended priorities in education, training and research. An Injury Prevention Initiative was established to address issues, implement priorities and develop an Ontario First Nation Injury Prevention Strategy and Action Plan. It is coordinated by the Chiefs in Ontario. Several projects were initiated to inform the development of the Strategy and Action Plan.

Objective The objective of the Ontario First Nations Environmental Scan on Injuries and Injury Prevention was to determine community-based injury issues, priorities, prevention initiatives and recommendations for injury prevention.

Methods The method utilised was to distribute a key informant survey to each First Nation community in Ontario. Participants were asked to report the most frequent injury occurrences, to identify injury priorities, barriers and prevention initiatives including best practises.

Results The results for children, identified falls and violence, for youth it was falls, violence and alcohol poisoning. Adults had motor vehicle collisions, violence, and alcohol poisoning, and elders reported falls, violence and alcohol poisoning. The lack of community involvement, education, training, research, and funding for injury prevention programs were identified broadly as recommendations.

Conclusion First Nations communities understand the challenges facing their population, and want to take steps to reduce the burden of injury in their communities. 